\title{
Stable Solid Electrolyte Interphase Formation Induced by Monoquat-Based Anchoring in Lithium Metal Batteries
}

\author{
Tianhong Zhou," Yan Zhao," Mario El Kazzi, Jang Wook Choi,* and Ali Coskun*
}

Cite This: ACS Energy Lett. 2021, 6, 1711-1718

Read Online

ACCESS |

山ll Metrics \& More

回国 Article Recommendations

Supporting Information

ABSTRACT: The lithium ( $\mathrm{Li}$ ) metal anode is considered to be a promising candidate for next-generation batteries but is impeded by $\mathrm{Li}$ dendrites and the resulting poor reversibility. Here, we introduce monoquat salts with an ability to anchor onto the $\mathrm{Li}$ metal surface through pyridine moieties as electrolyte additives. We systematically varied both the number and the spatial arrangement of anchoring units along with the number of positive charges bearing $\mathrm{PF}_{6}$ counteranions to probe their impact on $\mathrm{Li}$ metal protection. A high surface concentration of $\mathrm{PF}_{6}$ counteranions and their immediate reaction with the deposited $\mathrm{Li}$ facilitate the in situ formation and

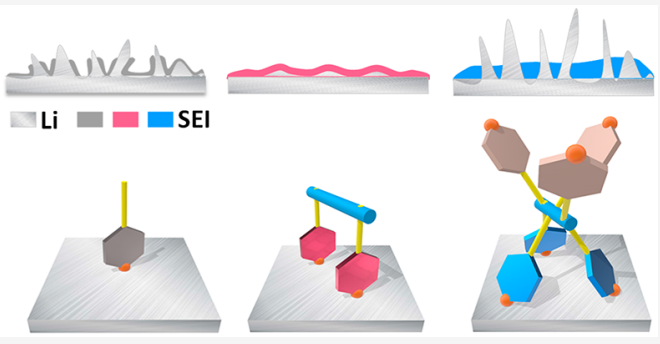
homogeneous distribution of $\mathrm{LiF}$ in the surface passivation layer. Our results revealed that the monoquat dication, through stable pyridine-based anchoring, formed an ionically conductive and dense solid electrolyte interphase layer and showed superior cycling performance in both ether-based and carbonate-based electrolytes, thus clearly demonstrating the importance of the anchoring strategy for Li metal surface protection.

$\mathrm{T}$ he significant increase in demand for advanced portable electronic devices, drones, and electric vehicles $(\mathrm{EVs})$ in recent years necessitates the development of next-generation Li-ion batteries (LIBs) that can outperform current LIBs with respect to their energy density. Accordingly, battery chemistries beyond the intercalation mechanism are widely pursued and investigated. In this direction, one of the most promising candidates is the $\mathrm{Li}$ metal anode because of its extremely low density $(0.534 \mathrm{~g}$ $\left.\mathrm{cm}^{-3}\right)$, lowest negative electrochemical potential $(-3.04 \mathrm{~V}$ vs the standard hydrogen electrode), and ultrahigh theoretical specific capacity $\left(3860 \mathrm{mAh} \mathrm{g}^{-1}\right){ }^{1,2}$ There are, however, still significant challenges to be addressed for the practical utilization of the Li metal anode. The uncontrolled Li dendrite growth induced by uneven Li-ion plating and stripping during cycling results in the formation of a large amount of "dead $\mathrm{Li}$ " and a thick solid electrolyte interphase (SEI) layer. This process naturally depletes the electrolyte, shortens the cycle life, and causes a significant safety risk. ${ }^{3,4}$

Intensive research efforts have been devoted to addressing these issues for practical application of the $\mathrm{Li}$ metal anode. First, to tackle infinite volume expansion, three-dimensional (3D) structures, such as $3 \mathrm{D}$ copper, one-dimensional carbon nanomaterials, and the $\mathrm{Li}_{x} \mathrm{Si}-\mathrm{Li}_{2} \mathrm{O}$ matrix, were used as hosts to accommodate plated $\mathrm{Li}$ by decreasing the effective current density or incorporating lithophilic functionality. ${ }^{5-9}$ Second, Li plating was guided by the seeded growth strategy; the overpotential reflective of the nucleation barrier was shown to be decreased by $\mathrm{Ag}$, $\mathrm{Au}$, and $\mathrm{Zn}$ seeds. ${ }^{1,10}$ Third, the passivation layer or artificial SEI layer on the Li metal surface was shown to impede electrolyte decomposition and to induce uniform Li-ion transport. ${ }^{11,12}$ Finally, solid electrolytes can also largely suppress $\mathrm{Li}$ dendrite growth because of their high Young's moduli. ${ }^{13,14}$ Compared to these approaches, electrolyte engineering by including a high concentration salt ${ }^{15}$ or functional additives, ${ }^{16}$ such as co-solvents, ${ }^{17,18} \mathrm{LiNO}_{3}$ and polysulfides, ${ }^{19} \mathrm{Cs}^{+}$and $\mathrm{Rb}^{+},{ }^{20}$ and ionic liquids, ${ }^{21}$ could be more preferred from a practical standpoint.

Schmulbach and co-workers showed that the dissolution of alkali metals in pyridine leads to the simultaneous reduction of pyridine and the formation of a reactive salt, namely $\mathrm{M} \cdot \mathrm{C}_{5} \mathrm{H}_{5} \mathrm{~N}$ $\left(\mathrm{M}=\mathrm{Li}^{+}, \mathrm{Na}^{+}\right.$, or $\left.\mathrm{Cs}^{+}\right){ }^{22}$ This study points to the possibility of using pyridine derivatives as anchoring units to form a homogeneous passivation layer on the surface of alkali metals. Inspired by these results, in this study, we not only introduce pyridine derivatives as electrolyte additives but also elucidate their key parameters, such as the number and spatial

Received: February 6, 2021

Accepted: March 18, 2021

Published: April 7, 2021 

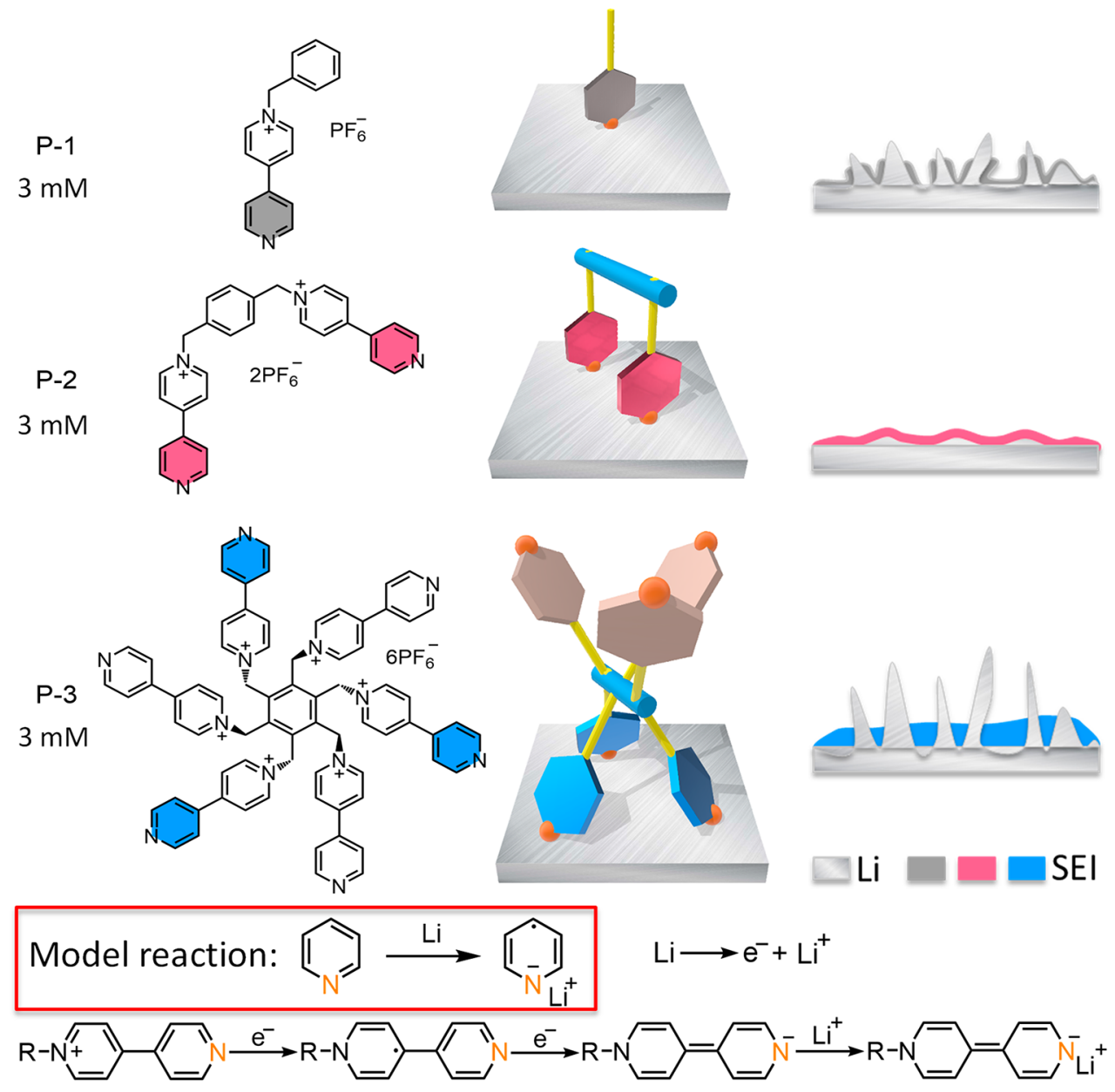

Figure 1. Chemical structures of the monoquarternized 4,4'-bipyridyl derivatives, namely, monoquat monocation, P-1, dimeric monoquat dication, P-2, and monoquat hexacation, P-3, as electrolyte additives at a concentration of $3 \mathrm{mM}$ and their proposed anchoring modes, along with $\mathrm{Li}$ deposition after cycling. The bottom panel shows the pyridine anchoring mechanism as well as the redox properties of the monoquat derivative.

arrangement of anchoring sites as well as the number of positive charges, focusing on the interfacial stabilization of the $\mathrm{Li}$ metal anode. From the design perspective, we targeted (Figure 1) monoquarternized 4,4'-bipyridyl derivatives bearing $\mathrm{PF}_{6}$ counteranions, namely, (1) monoquat monocation, P-1, with a single monopyridinium salt and one pyridine active anchoring site, (2) dimeric monoquat dication, P-2, with two monopyridinium salts and two pyridine active anchoring sites, and (3) tripodal monoquat hexacation, P-3, with six monopyridinium salts and six pyridine active bonding sites arranged in an alternating manner as electrolyte additives. The monopyridinium salts with $\mathrm{PF}_{6}$ counteranions were introduced into the structures of P-1, P-2, and P-3 to achieve in situ formation and a uniform distribution of $\mathrm{LiF}$ through the reaction between deposited $\mathrm{Li}$ and $\mathrm{PF}_{6}$ anions that are homogeneously distributed on the surface via a pyridineassisted anchoring approach. ${ }^{23} \mathrm{P}-1, \mathrm{P}-2$, and P-3 were synthesized according to literature reports (Figures S1S4). ${ }^{24-26}$ Whereas the gradual increase in the number of active anchoring sites is expected to form more efficient and stable coatings, P-3 is expected to promote growth on both faces of the molecule due to the alternating arrangement of pyridine moieties. Accordingly, we investigated P-1, P-2, and P-3 as electrolyte additives in both ether- and carbonate-based electrolytes to demonstrate the universal applicability of an anchoring strategy in various battery systems.

The HOMO and LUMO energies of the monoquat salts were calculated (Figure S5) using density functional theory calculation conducted at B3LYP/6-31G*. Whereas the LUMO energy levels were found to decrease going from P-1 to P-3, an opposite trend was observed for the HOMO energy levels. Higher HOMO and lower LUMO energy levels of monoquat salts relative to the electrolytes enable preferential oxidative decomposition at the cathode and reductive decomposition at the anode surface, respectively. According to the calculation results, while P-3 was the most active salt, which could form a thicker SEI layer, P-1 showed the lowest chemical reactivity. The comparative electrochemical analysis of P-1, P-2, and P-3 revealed the superior electrochemical performance of P-2 (Figure S6); thus, it was identified for further analysis and optimization. First, we investigated the effect of the concentration of P-2 in an ether-based electrolyte [1,3dioxolane and 1,2-dimethoxyethane (DOL-DME)]. Toward this end, we compared the galvanostatic cycling performances of LilLi symmetric cells with 0,3 , and $5 \mathrm{mM} \mathrm{P-2}$ in an etherbased electrolyte. The voltage polarization of the cell with 3 $\mathrm{mM} \mathrm{P}-2$ was found to be more stable under two different operation conditions: $3 \mathrm{~mA} \mathrm{~cm}{ }^{-2}$ with a capacity of $1 \mathrm{mAh}$ $\mathrm{cm}^{-2}$ and $2 \mathrm{~mA} \mathrm{~cm}^{-2}$ with a capacity of $4 \mathrm{mAh} \mathrm{cm}^{-2}$ (Figure 

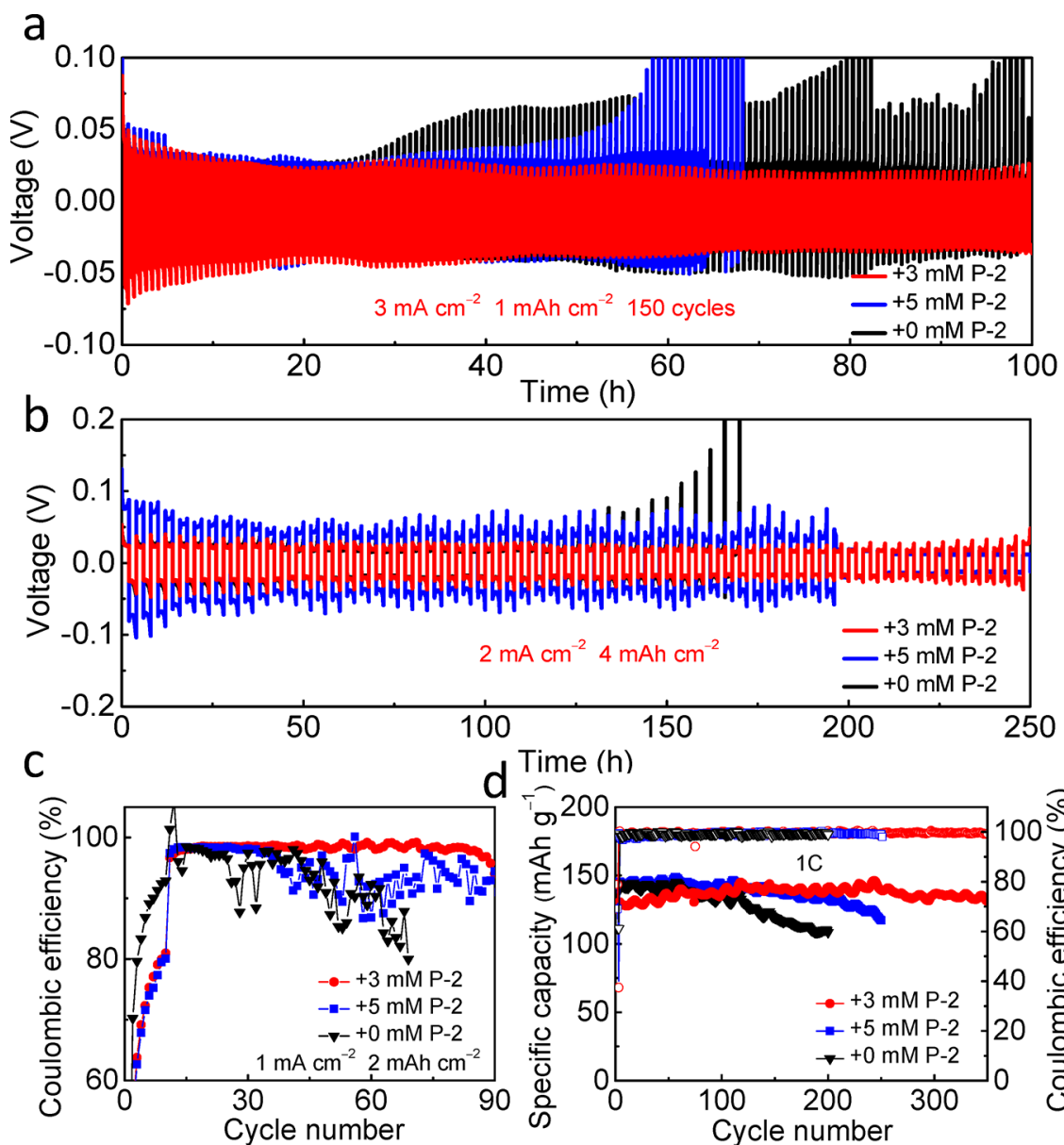

Time $(\mathrm{h})$

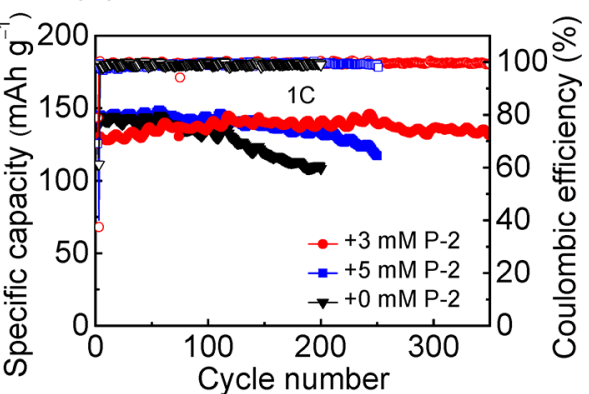

Figure 2. (a and b) Voltage-time profiles of symmetric cells with 0,3 , and $5 \mathrm{mM} \mathrm{P-2}$ additive in the ether-based electrolyte at $3 \mathrm{~mA} \mathrm{~cm}^{-2}$ with a cutoff capacity of $1 \mathrm{mAh} \mathrm{cm}$ and $2 \mathrm{~mA} \mathrm{~cm}{ }^{-2}$ with a cutoff capacity of $4 \mathrm{mAh} \mathrm{cm}^{-2}$. (c) CE stability over cycling for cells with 0 , 3 , and $5 \mathrm{mM} \mathrm{P-2}$ additive in the ether-based electrolyte at a current density of $1 \mathrm{~mA} \mathrm{~cm}{ }^{-2}$ with a capacity of $2 \mathrm{mAh} \mathrm{cm}$. (d) Cycling performance and CEs of $\mathrm{Li} / \mathrm{LFP}$ full cells with 0,3 , and $5 \mathrm{mM} \mathrm{P-2}$ additive in the ether-based electrolyte at $1 \mathrm{C}$.

2a,b). Coulombic efficiencies (CEs) of the $\mathrm{LilCu}$ asymmetric cells with the same ether-based electrolyte were assembled to further evaluate Li plating/stripping behavior. In this test, 3 mM P-2 maintained the most stable CE of $98.3 \%$ on average for 90 cycles when evaluated at $1 \mathrm{~mA} \mathrm{~cm}^{-2}$ with a capacity of 2 $\mathrm{mAh} \mathrm{cm}^{-2}$ (Figure $2 \mathrm{c}$ and Figure $\mathrm{S} 7$ ). The performance comparison of electrolyte additives is summarized in Table S1; compared to the previously reported additives, P-2 can operate at a larger Li capacity of $2 \mathrm{mAh} \mathrm{cm}^{-2}$. In addition, when tested in the $\mathrm{Li} / \mathrm{LiFePO}_{4}$ full cells with the limited lithium anode at 1 $\mathrm{C}\left(170 \mathrm{~mA} \mathrm{~g}^{-1}\right)$ - the preplated $\mathrm{Cu}$ foil with $2.3 \mathrm{mAh} \mathrm{cm}{ }^{-2} \mathrm{Li}$ paired with the LFP cathode $\left(2.5 \mathrm{mg} \mathrm{cm}^{-2}\right)$ gave a $\mathrm{N} / \mathrm{P}$ ratio of 5.4-the $3 \mathrm{mM} \mathrm{P-2}$ cell showed a superior cycling stability with a capacity of $131 \mathrm{mAh} \mathrm{g}_{\mathrm{LFP}}{ }^{-1}$ after 350 cycles (Figure $2 \mathrm{~d}$ ). Detailed potential profiles at different cycle numbers are presented in Figure S8. In addition, the morphology changes after Li plating in the 50 th cycle operated at $1 \mathrm{~mA} \mathrm{~cm}^{-2}$ with a $1 \mathrm{mAh} \mathrm{cm}^{-2}$ capacity were investigated by field emission scanning electron microscopy (FE-SEM) to probe the impact of P-2. The cell with $3 \mathrm{mM}$ P-2 exhibited (Figures S9 and S10) the most uniform and dense surface structure compared to those of the other two cells with different P-2 concentrations, thus pointing to $3 \mathrm{mM}$ as a P-2 concentration sweet spot.

Furthermore, the assessment of the P-2 additive was also expanded to the carbonate-based [ethylene carbonate and dimethyl carbonate (EC-DMC), 1:1 (v:v)] electrolyte to demonstrate its broad applicability. The changes in morphol-

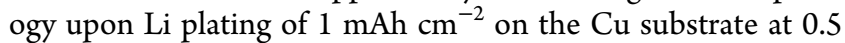
$\mathrm{mA} \mathrm{cm}{ }^{-2}$ with 0,3 , and $5 \mathrm{mM} \mathrm{P-2}$ were studied (Figure $3 \mathrm{a}-\mathrm{c}$ and Figure S11). For the electrolyte without P-2, Li plating occurred randomly and resulted in the formation of an uneven surface with a whisker morphology. Upon introduction of 3 mM P-2, the Li metal surface maintained a flat morphology. However, when the concentration of P-2 was further increased to $5 \mathrm{mM}$, the $\mathrm{Li}$ metal surface became porous, which originated from non-uniform plating in the presence of excess P-2. In addition, the Li metal morphology of $3 \mathrm{mM} \mathrm{P-2}$ still showed a smooth and dense surface after 50 cycles, compared to the lumpy and rough surface morphologies observed for 0 and $5 \mathrm{mM} \mathrm{P-2}$ after the same number of cycles (Figure S12).

The LilLi symmetric cells were further evaluated with 0,3 , and $5 \mathrm{mM}$ P-2 additives at $0.5 \mathrm{~mA} \mathrm{~cm}^{-2}$ and a capacity of 1 $\mathrm{mAh} \mathrm{cm}^{-2}$ in the carbonate-based electrolyte (Figure $3 \mathrm{~d}$ ). With $0 \mathrm{mM}$ P-2, the overpotential suddenly increased at $\sim 180$ $\mathrm{h}$, induced by uncontrolled side reactions originating from $\mathrm{Li}$ dendrite growth. In the presence of $5 \mathrm{mM}$ P-2, excess P-2 led to an increase in overpotential ascribed to the formation of a thick SEI layer. Notably, the $3 \mathrm{mM}$ P-2 cell exhibited stable polarization up to $350 \mathrm{~h}$ and also gave the best CE stability up to 100 cycles (Figure 3e). Furthermore, electrochemical impedance spectroscopy (EIS) of the LilLi symmetric cell was conducted to compare the interface behavior at different 

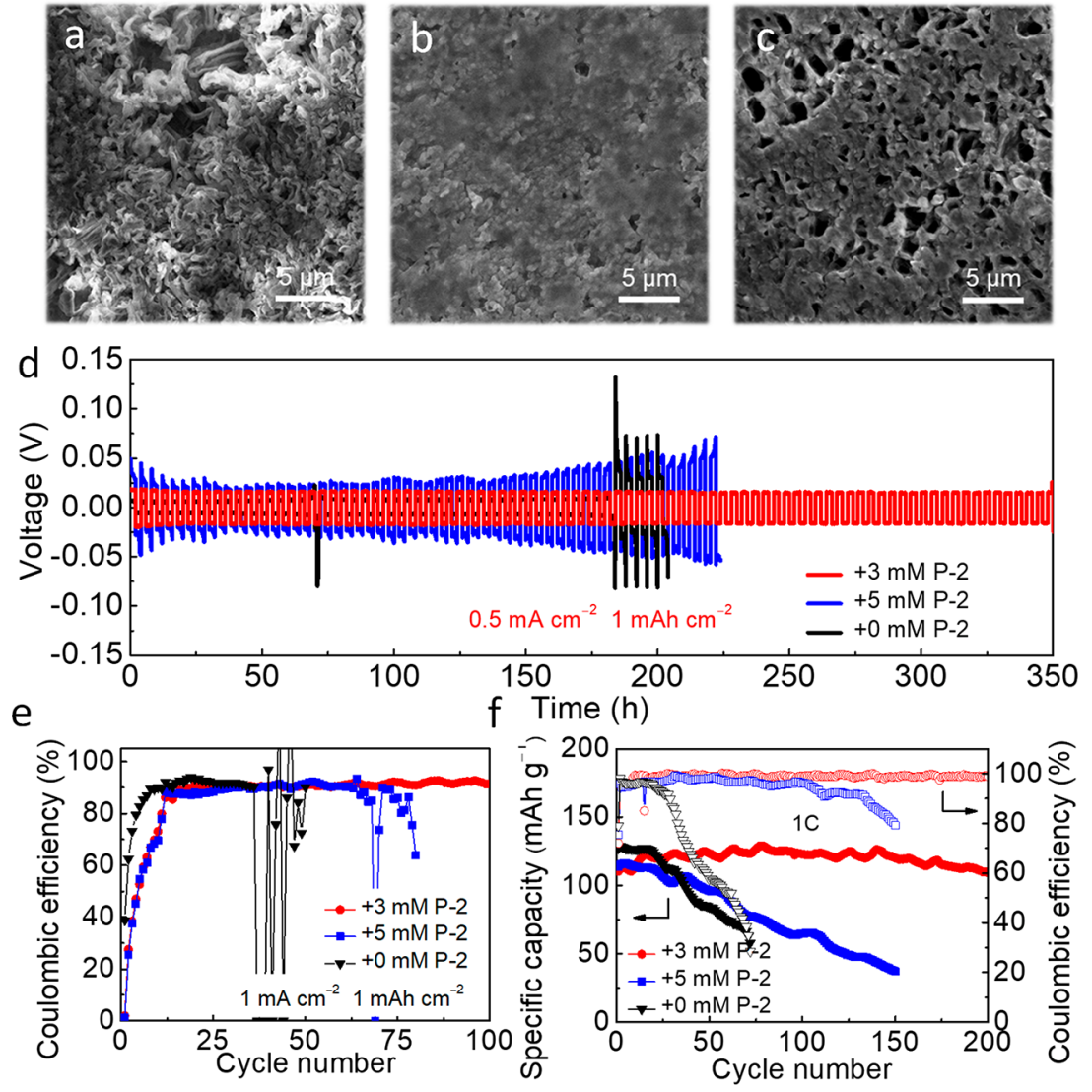

Figure 3. (a-c) SEM images of the Li plating morphology after the first cycle at $0.5 \mathrm{~mA} \mathrm{~cm}{ }^{-2}$ and $1 \mathrm{mAh} \mathrm{cm}^{-2}$ with 0,3 , and $5 \mathrm{mM} P-2$ additive in the carbonate-based electrolyte. (d) Voltage-time profiles of symmetric cells with 0,3 , and 5 mM P-2 additive in the carbonatebased electrolyte at $0.5 \mathrm{~mA} \mathrm{~cm}{ }^{-2}$ with a cutoff capacity of $1 \mathrm{mAh} \mathrm{cm}$. (e) CE stability over cycling for cells with 0,3 , and $5 \mathrm{mM} \mathrm{P-2} \mathrm{additive}$ in the carbonate-based electrolyte at a current density of $1 \mathrm{~mA} \mathrm{~cm}{ }^{-2}$ with a capacity of $1 \mathrm{mAh} \mathrm{cm}^{-2}$. (f) Cycling performance and CEs of Li/ LFP full cells with 0,3 , and $5 \mathrm{mM} \mathrm{P-2}$ additive in the carbonate-based electrolyte at $1 \mathrm{C}$.

additive concentrations (Figure S13). The higher concentration of the additive resulted in a larger interfacial resistance $\left(R_{\text {inter }}\right)$ after the first cycle, which can be explained by the surface coating via pyridine-based anchoring. After 10 cycles, 3 mM P-2 additive exhibited the lowest bulk resistance $\left(R_{\mathrm{b}}\right)$ of $8.3 \Omega$ and a charge transfer resistance $\left(R_{\mathrm{ct}}\right)$ of $12.4 \Omega$, an indication of the formation of a stable, dense interface, compared to the $0 \mathrm{mM}(30.9$ and $17.4 \Omega)$ and $5 \mathrm{mM} \mathrm{P-2}(10.0$ and $13.8 \Omega$ ) counterparts (details in Table S2). ${ }^{27,28} \mathrm{Li} /$ $\mathrm{LiFePO}_{4}$ full cells were tested at $1 \mathrm{C}\left(170 \mathrm{~mA} \mathrm{~g}^{-1}\right)$ for the 0,3 , and $5 \mathrm{mM}$ P-2 cells (Figure $3 \mathrm{f}$ ). The $0 \mathrm{mM}$ P-2 cell exhibited the worst cycling performance, with a drastic decrease in both $\mathrm{CE}$ and capacity after only 20 cycles. For the $5 \mathrm{mM}$ P- 2 cell, the CE was stable only up to 100 cycles. In contrast, the $3 \mathrm{mM}$ P-2 cell showed a superior stability in both the capacity retention and CE up to 200 cycles, which is consistent with the half-cell measurement results presented above. Therefore, it has been concluded that $3 \mathrm{mM}$ P-2 additive performs well in both ether-based and carbonate-based electrolytes through the formation of a stable anchoring interface.

To understand the superior electrochemical performance of P-2 compared to P-1 and P-3, we compared the impact of these additives on the Li metal anode surface by employing 3 $\mathrm{mM}$ solutions of each additive in a carbonate-based electrolyte. First, Li plating morphologies and thicknesses after the first $\mathrm{Li}$ plating-stripping cycle with a capacity of $1 \mathrm{mAh} \mathrm{cm}^{-2}$ at 0.5 $\mathrm{mA} \mathrm{cm}{ }^{-2}$ were investigated by SEM analysis (Figure $4 \mathrm{a}-\mathrm{c}$ ).
Whereas SEM images revealed the formation of a rough surface with pinholes on $\mathrm{Li}$ metal for the P-1 additive, P-2 showed a relatively planar and dense surface structure with no apparent cracks. In the case of P-3, however, we observed the formation of an ultrathick, porous SEI layer incorporating numerous random holes with diameters ranging from 5 to 20 $\mu \mathrm{m}$. More importantly, when the thickness of Li plating was compared after the first Li plating, P-2 showed the lowest value of $14 \mu \mathrm{m}$, verifying a dense plating morphology, compared to that of the blank electrolyte, $28 \mu \mathrm{m}$ (Figure S14), the P-1 additive, $19 \mu \mathrm{m}$, and the P-3 additive, $23 \mu \mathrm{m}$. After 50 plating/ stripping cycles at a current density of $1 \mathrm{~mA} \mathrm{~cm}^{-2}$ with a total capacity of $1 \mathrm{mAh} \mathrm{cm}^{-2}$ (Figure $4 \mathrm{~d}-\mathrm{f}$ ), P-2 still exhibited a smooth morphology with no signs of dendritic growth on the Li surface. In contrast, while the growth of irregularly shaped Li was clearly visible with the P-1 additive, the P-3 electrode displayed a mossy and disordered Li surface. We reasoned that P-1 with only one pyridine anchoring site may not interact strongly with the surface, resulting in a mechanical instability of the SEI layer, whereas the tripodal structure of P-3 incorporating alternating pyridine moieties with anchoring sites on both faces of the molecule induces relatively loose three-dimensional SEI layer formation with an increased thickness. By contrast, P-2 with two pyridine anchoring sites enables strong anchoring to the surface, thus giving rise to a compact SEI layer involving its uniform interaction with the $\mathrm{Li}$ surface. Energy-dispersive X-ray spectroscopy (EDS) element 


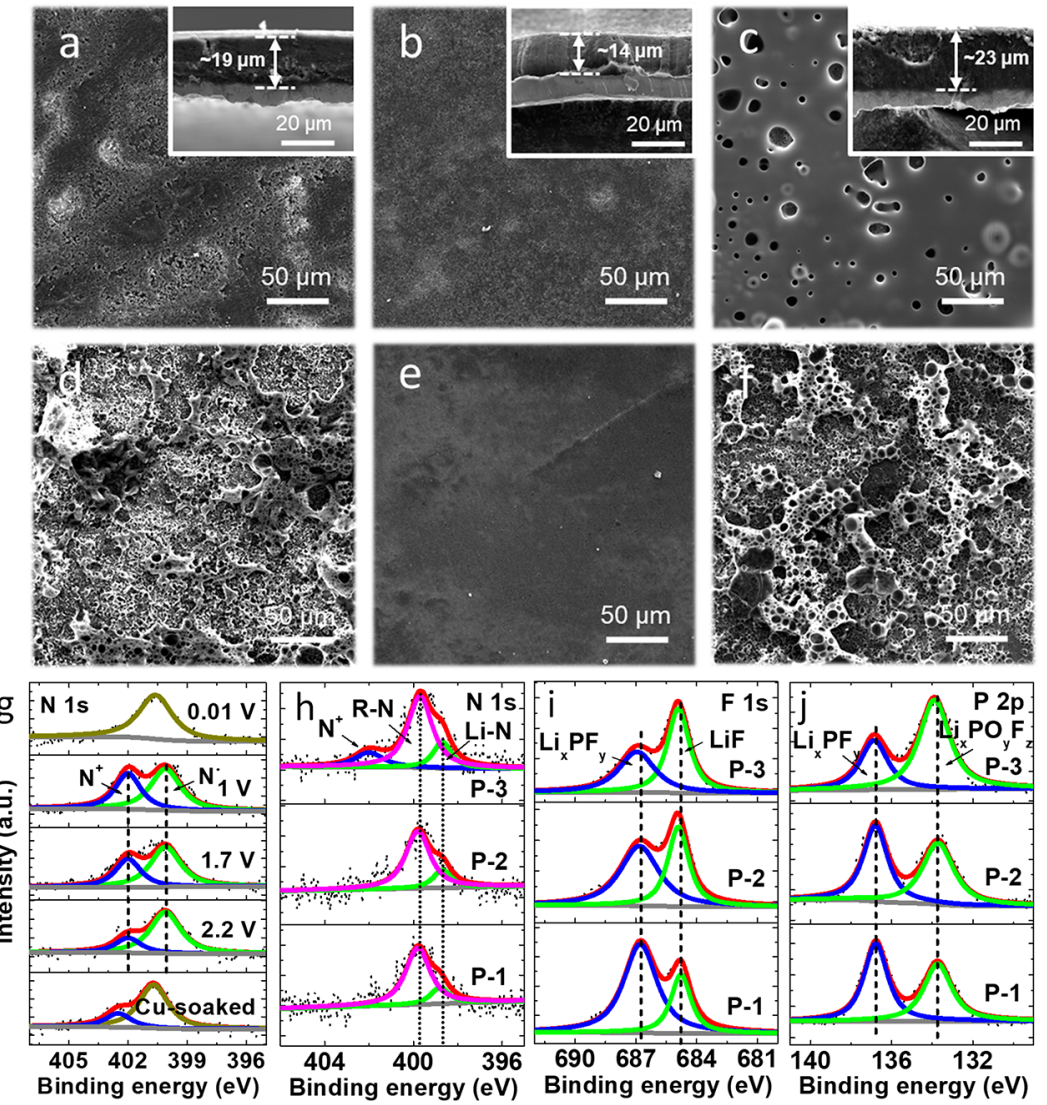

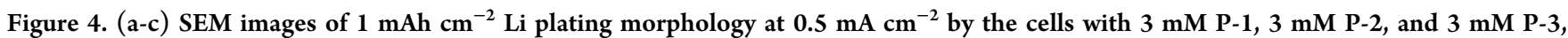
respectively, in the carbonate-based electrolyte (cross sections as insets) and (d-f) after 50 cycles at $1 \mathrm{~mA} \mathrm{~cm} \mathrm{~cm}^{-2}$ with $1 \mathrm{mAh} \mathrm{cm}^{-2} \mathrm{Li} \mathrm{by} \mathrm{the}$ cells with $3 \mathrm{mM} \mathrm{P-1,} 3 \mathrm{mM} \mathrm{P-2,} \mathrm{and} 3 \mathrm{mM} \mathrm{P-3}$, respectively, in the carbonate-based electrolyte. (g) N 1s XPS spectra of $3 \mathrm{mM}$ P-2 additive at different voltage points in the $\mathrm{Li}-\mathrm{Cu}$ cell by CV scanning. (h-j) XPS spectra of $\mathrm{N} \mathrm{1s}, \mathrm{F}$ 1s, and P 2p, respectively, of $3 \mathrm{mM} \mathrm{P-1,} 3 \mathrm{mM}$ P-2, and $3 \mathrm{mM} \mathrm{P-3}$ in the carbonate-based electrolyte after cycling.

mapping was conducted on the plated Li metal surface (Figure S15); compared to P-1 and P-3, P-2 exhibited uniform and compact anchoring as evidenced by homogeneous $\mathrm{N}$ and $\mathrm{LiF}$ distribution shown by $\mathrm{N}$ and $\mathrm{F}$ elemental mappings. These results clearly show the importance of the number of anchoring units as well as their spatial arrangement.

To elucidate the reaction mechanism of additives, cyclic voltammetry $(\mathrm{CV})$ experiments were performed for additives under both three-electrode and coin cell configurations (Figure S16). According to the three-electrode measurements (glassy carbon, $\mathrm{Pt}$, and $\mathrm{Ag} / \mathrm{AgCl}$ as the working electrode, counter electrode, and reference electrode, respectively), the reduction peaks shifted to a lower potential going from P-1 to P-3 due to the increased charge density, which revealed that the structure of the additives influenced the reduction potentials (Figure S16a). The reduction peaks of P-2 at -0.75 and $-1.1 \mathrm{~V}$ (vs $\mathrm{Ag} / \mathrm{AgCl}$ ) correspond to the peaks at 2.3 and $2.0 \mathrm{~V}\left(\mathrm{vs} \mathrm{Li}^{+} / \mathrm{Li}\right)$ in the coin cell with the carbonate-based electrolyte, respectively. $^{29}$ For reference, the reduction peak at $\sim 1.5 \mathrm{~V}$ (vs $\mathrm{Li}^{+} / \mathrm{Li}$ ) in the coin cell originated from electrolyte reduction, as verified by the $\mathrm{CV}$ profiles of the blank carbonate-based electrolyte (Figure S16c,d). ${ }^{30}$ In addition, the $\mathrm{CV}$ result of the $4,4^{\prime}$-bipyridine sample showed a single reduction peak at $-0.9 \mathrm{~V}$ (vs $\mathrm{Ag} / \mathrm{AgCl}$ ) (Figure $\mathrm{S} 16 \mathrm{~b}$ ). It should be emphasized that the reversible redox reaction happened in only a three-electrode system, but the corresponding redox reaction is found to be irreversible in the coin cell, which points to SEI formation by the monoquat additive. $^{29}$ Accordingly, the proposed redox mechanism (Figure 1) is the reduction of $\mathrm{N}^{+}$to form radicals at -0.75 $\mathrm{V}$ and the subsequent reduction of pyridine at $-1.1 \mathrm{~V}$ to form the corresponding anion. Clearly, after the first cycle, the reduction peaks at 2.3 and $2 \mathrm{~V}\left(\mathrm{vs} \mathrm{Li}^{+} / \mathrm{Li}\right)$ disappeared (Figure S16c), indicating the irreversible reductions of P-1, P-2, and P3 to form a protection layer on the Li metal anode surface. ${ }^{29}$

$\mathrm{X}$-ray photoelectron spectroscopy (XPS) analysis, which is used extensively to probe SEI structure evolution, ${ }^{18,31}$ was carried out to improve our understanding of the reduction behavior of additives and the differences in the SEI layer composition (Figure $4 \mathrm{~g}-\mathrm{j}$ ). As the additives vary only in terms of the number and spatial arrangement of monoquat units, we chose P-2 to study the reduction mechanism at different voltage points using the $\mathrm{Li}-\mathrm{Cu}$ asymmetric cell in a carbonatebased electrolyte (Figure S17a). Ex situ XPS was used to reveal additive reduction; compared to pristine P-2 deposited on $\mathrm{Cu}$ foil, $\mathrm{N} 1$ s spectra of the $\mathrm{Li}-\mathrm{Cu}$ asymmetric cell obtained at 2.2 $\mathrm{V}$ (vs $\mathrm{Li}^{+} / \mathrm{Li}$ ) exhibited a red-shift to 400 and $402 \mathrm{eV}$, which were assigned to $\mathrm{N}^{\bullet}$ and $\mathrm{N}^{+}$, respectively. ${ }^{32}$ When the voltage was decreased to $1 \mathrm{~V}\left(\mathrm{vs} \mathrm{Li}^{+} / \mathrm{Li}\right)$, the relative signal of $\mathrm{N}^{\bullet}$ in the $\mathrm{N}$ 1s spectra dropped gradually such that the areal ratio of $\mathrm{N}^{\bullet}$ decreased from $0.77(2.2 \mathrm{~V})$ to $0.63(1.7 \mathrm{~V})$ to $0.58(1 \mathrm{~V})$. At $0.01 \mathrm{~V}$ ( vs $\mathrm{Li}^{+} / \mathrm{Li}$ ), the new single $\mathrm{N}$ 1s peak emerged, which is presumably a strong indication of the neutral $\mathrm{N}$ bonding. The stepwise XPS characterization confirmed the reduction mechanism in Figure 1 , that is, the formation of $\mathrm{N}^{\bullet}$ and then bonding on the Li metal surface. Furthermore, we 


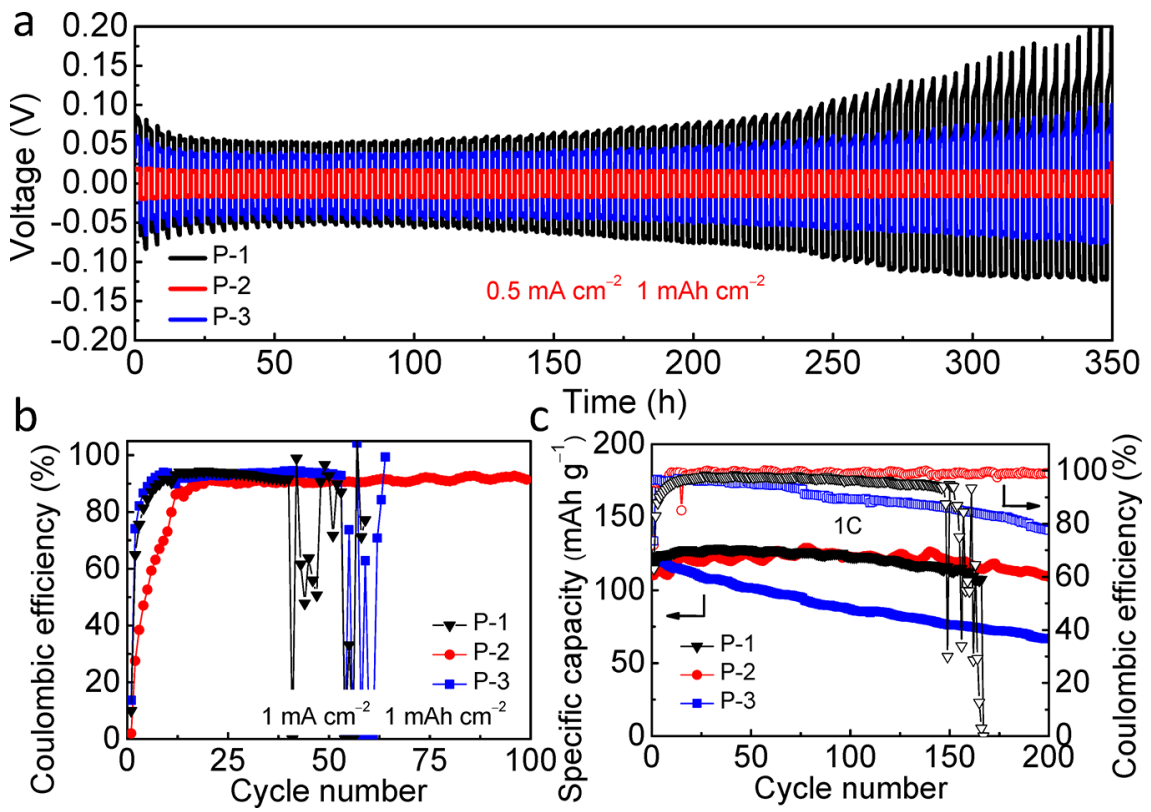

Figure 5. (a) Voltage-time profiles of symmetric cells with P-1, P-2, and P-3 additives at $0.5 \mathrm{~mA} \mathrm{~cm}$-2 with a cutoff capacity of $1 \mathrm{mAh} \mathrm{cm}^{-2}$ in the carbonate-based electrolyte. (b) CE stability over cycling for cells with P-1, P-2, and P-3 additives at a current density of $1 \mathrm{~mA} \mathrm{~cm}^{-2}$ with a capacity of $1 \mathrm{mAh} \mathrm{cm}$ in the carbonate-based electrolyte. (c) Cycling performance and CEs of Li/LFP full cells with P-1, P-2, and P3 at $1 \mathrm{C}$ in the carbonate-based electrolyte.

also conducted XPS analysis of P-1, P-2, and P-3 additives in $\mathrm{Li}-\mathrm{Cu}$ cells after 10 cycles at $1 \mathrm{~mA} \mathrm{~cm}$ of $0.5 \mathrm{mAh} \mathrm{cm}{ }^{-2}$ (Figure $4 \mathrm{~h}-\mathrm{j}$ ). It was clear that $\mathrm{N} 1 \mathrm{~s}$ profiles showed a residual $\mathrm{N}^{+}$peak in the case of $\mathrm{P}-3$ compared to P-1 and P-2, which points to the fact that the P-3 additive was difficult to fully reduce and the residual $\mathrm{N}^{+}$in the SEI layer leads to an uneven Li-ion flux and non-uniform SEI growth. Notably, the $\mathrm{N}-\mathrm{Li}$ bonding peak at $398.7 \mathrm{eV}$ proves unequivocally the pyridinebased anchoring mechanism for all additives. ${ }^{33}$ To probe the formation of $\mathrm{LiF}$ through the reaction of $\mathrm{PF}_{6}$ with deposited $\mathrm{Li}$, we also performed XPS F 1s analysis. F 1s peaks revealed the presence of $\mathrm{LiF}$ at $684.8 \mathrm{eV}$ in all of the additives. ${ }^{34}$ Interestingly, we observed an increase in the amount of LiF, with an increasing number of charges, which is expected as we have one, two, and six $\mathrm{PF}_{6}$ counteranions in P-1, P-2, and P-3, respectively. This finding is rather important as it demonstrates the ability to control $\mathrm{LiF}$ content by tuning the chemical structure of the additive. P $2 p$ peaks of P-3 showed the largest amount of $\mathrm{Li}_{x} \mathrm{PO}_{y} \mathrm{~F}_{z}$ at $133.8 \mathrm{eV}$ owing to the side reactions with $\mathrm{Li}$ metal, which increased the interface resistance and $\mathrm{Li}$ ion transport resistance during cycling. ${ }^{35,36}$ It is important to note that the suppression of $\mathrm{Li}_{x} \mathrm{PO}_{y} \mathrm{~F}_{z}$ formation is critical for achieving a uniform current distribution. ${ }^{37}$ Among all of the additives tested, P-2 is the only one with a high LiF and low $\mathrm{Li}_{x} \mathrm{PO}_{y} \mathrm{~F}_{z}$ combination, thus showing P-2's ability to induce a desirable interfacial layer with high mechanical stability and decent Li-ion conductivity.

The electrochemical performances of P-1, P-2, and P-3 were evaluated in the LilLi symmetric cells at a current density of 0.5 $\mathrm{mA} \mathrm{cm}{ }^{-2}$ and a capacity of $1 \mathrm{mAh} \mathrm{cm}{ }^{-2}$ in a carbonate-based electrolyte (Figure 5a). After Li plating/stripping for $350 \mathrm{~h}$, a stable voltage of $\sim 20 \mathrm{mV}$ was achieved with P-2, which is attributed to homogeneous $\mathrm{Li}$ plating/stripping behavior. However, in the case of $\mathrm{P}-1$, the overpotential increased rapidly to $200 \mathrm{mV}$, indicating serious side reactions at the $\mathrm{Li}$ metal interface. As for P-3, the voltage kept increasing but more slowly than P-1 due to more enhanced interfacial stability, presumably due to the higher number of pyridine anchoring sites. We also compared the CEs of P-1, P-2, and P3 at a current density of $1 \mathrm{~mA} \mathrm{~cm}{ }^{-2}$ with a capacity of $1 \mathrm{mAh}$ $\mathrm{cm}^{-2}$ (Figure 5b). P-2 maintained the average CE of $90.7 \%$ for 100 cycles, which was superior to the performance of P-3 (similar CE maintained for only 53 cycles) and P-1 (decreased to $<50 \%$ after only 45 cycles). The smallest polarization of P-2 shown in charge-discharge profiles during cycling was once again attributed to a smooth and uniform Li plating/stripping process by the stable pyridine-based anchoring of P-2 (Figure S18). As shown in Figure $5 \mathrm{c}$, the $\mathrm{Li} / \mathrm{LiFePO}_{4}$ full cells were assembled with different additives. The P-2 cell exhibited the best cyclability such that it retained a capacity of $110 \mathrm{mAh}$ $\mathrm{g}_{\mathrm{LFP}}{ }^{-1}$ after 200 cycles at $1 \mathrm{C}\left(170 \mathrm{~mA} \mathrm{~g}^{-1}\right)$, whereas the P-1 full cell exhibited a sudden fluctuation in $\mathrm{CE}$ and a short cycle life and ceased to operate after 147 cycles. P-2 showed superior capacity retention (84.6\%) after 200 cycles compared to that of P-3 (55.4\%). We attribute this result to the effective and homogeneous anchoring of P-2 onto the Li metal surface and to in situ $\mathrm{LiF}$ formation, thus keeping the $\mathrm{Li}$ metal interface from unwanted irreversible parasitic reactions, whereas P-1 and P-3 suffered from more severe $\mathrm{Li}$ dendrite growth and the resulting side reactions. The composition of CEI was characterized by XPS for the $\mathrm{Li} / \mathrm{LiFePO}_{4}$ full cells after 10 cycles containing monoquat salts in a carbonate-based electrolyte (Figure S19). F 1s spectra revealed that the amount of $\mathrm{LiF}$ decreased significantly in the presence of monoquat salts. A similar phenomenon was also reported for $\mathrm{FEC}^{38}$ and fluorinated malonatoborate ${ }^{39}$ additives. As the decomposition of $\mathrm{LiPF}_{6}$ is suppressed on the cathode surface in the presence of additives, a suitable LiF source (P-2) would improve the CEI stability. Excess LiF formation in the absence of additives in the carbonate-based electrolyte can form a highly resistive film. In addition, in XPS $\mathrm{P} 2 \mathrm{p}$ profiles, the $\mathrm{P}-2$ additive exhibited a smaller amount of $\mathrm{Li}_{x} \mathrm{PO}_{y} \mathrm{~F}_{z} \cdot \mathrm{Li}_{x} \mathrm{PO}_{y} \mathrm{~F}_{z}$ was 
previously shown to increase the interfacial resistance and $\mathrm{Li}$ ion transport resistance of the CEI layer. ${ }^{35,36}$ Therefore, in agreement with the SEI composition results, the P-2 additive showed a superior CEI composition. Comparative EIS analyses of LilLi symmetric cells using P-1, P-2, and P-3 were conducted to evaluate the interfacial stability and lithium transport behavior (Figure S20). After the first cycle, all of the additives were electrochemically reduced as a coating layer on the surface of the $\mathrm{Li}$ metal anode. The interfacial resistance $\left(R_{\text {inter }}\right)$ increased going from $\mathrm{P}-1$ to $\mathrm{P}-3$, stemming from the increased thickness of the interfacial layer. ${ }^{27}$ However, the P-2 cell showed the smallest charge transfer resistance $\left(R_{\mathrm{ct}}=10.5\right.$ $\Omega)$, supporting its efficient ion transport at the interface. The larger $R_{\mathrm{ct}}$ of P-1 and P-3 cells reflected a relatively sluggish electrode-electrolyte interface. After 10 cycles, the lowest bulk $R_{\mathrm{b}}(8.3 \Omega)$ and interface resistance $R_{\text {inter }}(6.2 \Omega)$ values were obtained from P-2 cells and this result was once again ascribed to formation of the thin, flat, and dense interface during $\mathrm{Li}$ plating/stripping. Cells incorporating P-1 and P-3 showed a larger resistance possibly due the mechanical instability of the SEI layer by a single anchoring site of P-1 and a rough and porous interface induced by the uneven ion flux originating from the dual direction and tripod structure of P-3, respectively, which were in good agreement with the aforementioned results of $\mathrm{Li}$ metal morphology and electrochemical performance. ${ }^{40}$ As for the practical applications, highloading commercial NCM811 cathodes (8 and $20 \mathrm{mg} \mathrm{cm}^{-2}$ ) were paired with ultrathin $\mathrm{Li}$ foil $(20$ and $50 \mu \mathrm{m})$ using a carbonate electrolyte with $3 \mathrm{mM} \mathrm{P}-2$ additive (Figure S21). Cells were tested at $1 \mathrm{C}\left(200 \mathrm{~mA} \mathrm{~g}^{-1}\right)$, and the $\mathrm{N} / \mathrm{P}$ ratio was 2.5. Both full cells showed clear improvements in performance in the presence of the P-2 additive.

In summary, we demonstrated that the monoquat-based anchoring strategy is useful in effectively stabilizing the $\mathrm{Li}$ metal interface, in which both the number and spatial arrangement of pyridine moieties are shown to be critical. Upon optimization of the additive concentration and structure, the dense and flat morphology of the Li metal deposit were obtained through strong anchoring with Li metal, resulting in a decreased interfacial resistance. Moreover, it has also been shown that chemical structures of the additives have a profound impact on the composition of the SEI layer. The integration of pyridinium cations bearing $\mathrm{PF}_{6}$ counteranions also enabled a high surface concentration of anions, thus facilitating the formation of $\mathrm{LiF}$ as well as its homogeneous distribution. In broader terms, this strategy can generally be applied to other reactive electrodes that suffer from interfacial instability originating from undesired morphology evolution.

\section{ASSOCIATED CONTENT}

\section{SI Supporting Information}

The Supporting Information is available free of charge at https://pubs.acs.org/doi/10.1021/acsenergylett.1c00274.

Experimental details, ${ }^{1} \mathrm{H}$ NMR and ${ }^{13} \mathrm{C}$ NMR spectra, CE profiles, voltage profiles, SEM, CV, XPS, and EIS data, and fitting results with an equivalent circuit (PDF)

\section{AUTHOR INFORMATION}

\section{Corresponding Authors}

Ali Coskun - Department of Chemistry, University of Fribourg, Fribourg 1700, Switzerland; (1) orcid.org/00000002-4760-1546; Email: ali.coskun@unifr.ch
Jang Wook Choi - School of Chemical and Biological Engineering, Department of Materials Science and Engineering, and Institute of Chemical Processes, Seoul National University, Seoul 08826, Republic of Korea; (ㄱ) orcid.org/0000-0001-8783-0901;

Email: jangwookchoi@snu.ac.kr

\section{Authors}

Tianhong Zhou - Department of Chemistry, University of Fribourg, Fribourg 1700, Switzerland; (1) orcid.org/00000002-9537-8465

Yan Zhao - Department of Chemistry, University of Fribourg, Fribourg 1700, Switzerland; (1) orcid.org/0000-0001-53245050

Mario El Kazzi - Electrochemistry Laboratory, Paul Scherrer Institut, Villigen 5232, Switzerland; (1) orcid.org/00000003-2975-0481

Complete contact information is available at:

https://pubs.acs.org/10.1021/acsenergylett.1c00274

\section{Author Contributions}

${ }$ T.Z. and Y.Z. contributed equally to this work.

Notes

The authors declare no competing financial interest.

\section{ACKNOWLEDGMENTS}

A.C. acknowledges the Swiss National Science Foundation (SNF) for funding of this research (200021-188572). J.W.C. acknowledges the support from the National Research Foundation of Korea (NRF) (Grants NRF2018R1A2A1A19023146, NRF-2017M1A2A2044504, NRF2020M3H4A3081874, and NRF-2018M1A2A2063340), the Technology Innovation Program (20012341) funded by the Ministry of Trade, Industry \& Energy (MOTIE) of Korea, and generous support from the Institute of Engineering Research (IER) at Seoul National University.

\section{REFERENCES}

(1) Lin, D.; Liu, Y.; Cui, Y. Reviving the lithium metal anode for high-energy batteries. Nat. Nanotechnol. 2017, 12, 194-206.

(2) Choi, J. W.; Aurbach, D. Promise and reality of post-lithium-ion batteries with high energy densities. Nat. Rev. Mater. 2016, 1, 16013.

(3) Kwon, T.-W.; Choi, J. W.; Coskun, A. Prospect for supramolecular chemistry in high-energy-density rechargeable batteries. Joule 2019, 3, 662-682.

(4) Cheng, X. B.; Zhang, R.; Zhao, C. Z.; Zhang, Q. Toward safe lithium metal anode in rechargeable batteries: A Review. Chem. Rev. 2017, 117, 10403-10473.

(5) Yun, Q.; He, Y.-B.; Lv, W.; Zhao, Y.; Li, B.; Kang, F.; Yang, Q.$\mathrm{H}$. Chemical dealloying derived $3 \mathrm{D}$ porous current collector for $\mathrm{Li}$ metal anodes. Adv. Mater. 2016, 28, 6932-6939.

(6) Lin, D.; Zhao, J.; Sun, J.; Yao, H.; Liu, Y.; Yan, K.; Cui, Y. Threedimensional stable lithium metal anode with nanoscale lithium islands embedded in ionically conductive solid matrix. Proc. Natl. Acad. Sci. U. S. A. 2017, 114, 4613-4618.

(7) Zhou, T.; Zhao, Y.; Choi, J. W.; Coskun, A. Lithium-salt mediated synthesis of a covalent triazine framework for highly stable lithium metal batteries. Angew. Chem., Int. Ed. 2019, 58, 1679516799.

(8) Yoo, D. J.; Elabd, A.; Choi, S.; Cho, Y.; Kim, J.; Lee, S. J.; Choi, S. H.; Kwon, T. W.; Char, K.; Kim, K. J.; Coskun, A.; Choi, J. W. Highly elastic polyrotaxane binders for mechanically stable lithium hosts in lithium-metal batteries. Adv. Mater. 2019, 31, 1901645.

(9) Shi, P.; Li, T.; Zhang, R.; Shen, X.; Cheng, X. B.; Xu, R.; Huang, J. Q.; Chen, X. R.; Liu, H.; Zhang, Q. Lithiophilic $\mathrm{LiC}_{6}$ layers on 
carbon hosts enabling stable Li metal anode in working batteries. Adv. Mater. 2019, 31, No. 1807131.

(10) Yang, C.; Yao, Y.; He, S.; Xie, H.; Hitz, E.; Hu, L. Ultrafine silver nanoparticles for seeded lithium deposition toward stable lithium metal anode. Adv. Mater. 2017, 29, 1702714.

(11) Liu, X.; Liu, J.; Qian, T.; Chen, H.; Yan, C. Novel Organophosphate-derived dual-layered interface enabling air-stable and dendrite-free lithium metal anode. Adv. Mater. 2020, 32, No. 1902724.

(12) Liu, Y.; Lin, D.; Yuen, P. Y.; Liu, K.; Xie, J.; Dauskardt, R. H.; Cui, Y. An artificial solid electrolyte interphase with high Li-ion conductivity, mechanical strength, and flexibility for stable lithium metal anodes. Adv. Mater. 2017, 29, 1605531.

(13) Lu, Q.; He, Y.-B.; Yu, Q.; Li, B.; Kaneti, Y. V.; Yao, Y.; Kang, F.; Yang, Q.-H. Dendrite-free, high-rate, long-life lithium metal batteries with a 3D cross-linked network polymer electrolyte. Adv. Mater. 2017, 29, 1604460.

(14) Wu, H.; Cao, Y.; Su, H.; Wang, C. Tough gel electrolyte using double polymer network design for the safe, stable cycling of lithium metal anode. Angew. Chem., Int. Ed. 2018, 57, 1361-1365.

(15) Qian, J.; Henderson, W. A.; Xu, W.; Bhattacharya, P.; Engelhard, M.; Borodin, O.; Zhang, J. G. High rate and stable cycling of lithium metal anode. Nat. Commun. 2015, 6, 6362.

(16) Ota, H.; Shima, K.; Ue, M.; Yamaki, J.-I. Effect of vinylene carbonate as additive to electrolyte for lithium metal anode. Electrochim. Acta 2004, 49, 565-572.

(17) Wang, D.; Zhang, F.; He, P.; Zhou, H. A versatile halide ester enabling Li-anode stability and a high rate capability in lithium-oxygen batteries. Angew. Chem., Int. Ed. 2019, 58, 2355-2359.

(18) Cao, X.; Ren, X.; Zou, L.; Engelhard, M. H.; Huang, W.; Wang, H.; Matthews, B. E.; Lee, H.; Niu, C.; Arey, B. W.; Cui, Y.; Wang, C.; Xiao, J.; Liu, J.; Xu, W.; Zhang, J.-G. Monolithic solid-electrolyte interphases formed in fluorinated orthoformate-based electrolytes minimize Li depletion and pulverization. Nat. Energy 2019, 4, 796805.

(19) Aurbach, D.; Pollak, E.; Elazari, R.; Salitra, G.; Kelley, C. S.; Affinito, $\mathrm{J}$. On the surface chemical aspects of very high energy density, rechargeable Li-sulfur batteries. J. Electrochem. Soc. 2009, 156, A694.

(20) Ding, F.; Xu, W.; Graff, G. L.; Zhang, J.; Sushko, M. L.; Chen, X.; Shao, Y.; Engelhard, M. H.; Nie, Z.; Xiao, J.; Liu, X.; Sushko, P. V.; Liu, J.; Zhang, J.-G. Dendrite-free lithium deposition via self-healing electrostatic shield mechanism. J. Am. Chem. Soc. 2013, 135, 44504456

(21) Yoo, D.-J.; Kim, K. J.; Choi, J. W. The synergistic effect of cation and anion of an ionic liquid additive for lithium metal anodes. Adv. Energy Mater. 2018, 8, 1702744.

(22) Schmulbach, C. D.; Hinckley, C. C.; Wasmund, D. Solutions of alkali metals in anhydrous pyridine. J. Am. Chem. Soc. 1968, 90, $6600-6602$.

(23) Lee, S.-Y.; Shangguan, J.; Alvarado, J.; Betzler, S.; Harris, S. J.; Doeff, M. M.; Zheng, H. Unveiling the mechanisms of lithium dendrite suppression by cationic polymer film induced solidelectrolyte interphase modification. Energy Environ. Sci. 2020, 13, $1832-1842$

(24) Hou, S.; Chen, N.; Zhang, P.; Dai, S. Heterogeneous viologen catalysts for metal-free and selective oxidations. Green Chem. 2019, $21,1455-1460$.

(25) Zhu, Z.; Li, H.; Liu, Z.; Lei, J.; Zhang, H.; Botros, Y. Y.; Stern, C. L.; Sarjeant, A. A.; Stoddart, J. F.; Colquhoun, H. M. Oligomeric pseudorotaxanes adopting infinite-chain lattice superstructures. Angew. Chem., Int. Ed. 2012, 51, 7231-7235.

(26) Guo, Q.-H.; Liu, Z.; Li, P.; Shen, D.; Xu, Y.; Ryder, M. R.; Chen, H.; Stern, C. L.; Malliakas, C. D.; Zhang, X.; Zhang, L.; Qiu, Y.; Shi, Y.; Snurr, R. Q.; Philp, D.; Farha, O. K.; Stoddart, J. F. A hierarchical nanoporous diamondoid superstructure. Chem. 2019, 5, $2353-2364$.
(27) Zhang, S. S.; Xu, K.; Jow, T. R. EIS study on the formation of solid electrolyte interface in Li-ion battery. Electrochim. Acta 2006, 51, $1636-1640$

(28) Lu, Y.; Gu, S.; Hong, X.; Rui, K.; Huang, X.; Jin, J.; Chen, C.; Yang, J.; Wen, Z. Pre-modified $\mathrm{Li}_{3} \mathrm{PS}_{4}$ based interphase for lithium anode towards high-performance Li-S battery. Energy Storage Mater. 2018, 11, 16-23.

(29) Wu, H.; Cao, Y.; Geng, L.; Wang, C. In situ formation of stable interfacial coating for high performance lithium metal anodes. Chem. Mater. 2017, 29, 3572-3579.

(30) Kawaguchi, T.; Shimada, K.; Ichitsubo, T.; Yagi, S.; Matsubara, E. Surface-layer formation by reductive decomposition of $\mathrm{LiPF}_{6}$ at relatively high potentials on negative electrodes in lithium ion batteries and its suppression. J. Power Sources 2014, 271, 431-436.

(31) Gao, Y.; Rojas, T.; Wang, K.; Liu, S.; Wang, D.; Chen, T.; Wang, H.; Ngo, A. T.; Wang, D. Low-temperature and high-ratecharging lithium metal batteries enabled by an electrochemically active monolayer-regulated interface. Nat. Energy 2020, 5, 534-542.

(32) Cao, L.; Fang, G.; Wang, Y. Electroreduction of viologen phenyl diazonium salts as a strategy to control viologen coverage on electrodes. Langmuir 2017, 33, 980-987.

(33) Guo, Y.; Niu, P.; Liu, Y.; Ouyang, Y.; Li, D.; Zhai, T.; Li, H.; Cui, Y. An autotransferable g- $\mathrm{C}_{3} \mathrm{~N}_{4} \mathrm{Li}^{+}$modulating layer toward stable lithium anodes. Adv. Mater. 2019, 31, 1900342.

(34) Son, S. B.; Cao, L.; Yoon, T.; Cresce, A.; Hafner, S. E.; Liu, J.; Groner, M.; Xu, K.; Ban, C. Interfacially induced cascading failure in graphite-silicon composite anodes. Adv. Sci. 2019, 6, 1801007.

(35) Yu, X.; Wang, Y.; Cai, H.; Shang, C.; Liu, Y.; Wang, Q. Enhancing the stability of high-voltage lithium-ion battery by using sulfur-containing electrolyte additives. Ionics 2019, 25, 1447-1457.

(36) Cheng, M.; Tang, W.; Li, Y.; Zhu, K. Study on compositions and changes of SEI film of $\mathrm{Li}_{2} \mathrm{MnO}_{3}$ positive material during the cycles. Catal. Today 2016, 274, 116-122.

(37) Kuwata, H.; Sonoki, H.; Matsui, M.; Matsuda, Y.; Imanishi, N. Surface layer and morphology of lithium metal electrodes. Electrochemistry 2016, 84, 854-860.

(38) Wu, B.; Ren, Y.; Mu, D.; Liu, X.; Zhao, J.; Wu, F. Enhanced electrochemical performance of $\mathrm{LiFePO}_{4}$ cathode with the addition of fluoroethylene carbonate in electrolyte. J. Solid State Electrochem. 2013, 17, 811-816.

(39) Han, J.-G.; Lee, J. B.; Cha, A.; Lee, T. K.; Cho, W.; Chae, S.; Kang, S. J.; Kwak, S. K.; Cho, J.; Hong, S. Y.; Choi, N.-S. Unsymmetrical fluorinated malonatoborate as an amphoteric additive for high-energy-density lithium-ion batteries. Energy Environ. Sci. 2018, 11, 1552-1562.

(40) Bieker, G.; Winter, M.; Bieker, P. Electrochemical in situ investigations of SEI and dendrite formation on the lithium metal anode. Phys. Chem. Chem. Phys. 2015, 17, 8670-8679. 